\title{
Biochemical properties of Streptococcus sobrinus reisolates from the gastrointestinal tract of a gnotobiotic rat
}

\author{
M. D. P. Willcox, ${ }^{1 *}$ R. J. Fitzgerald, ${ }^{2}$ B. O. Adams, ${ }^{2}$ M. Patrikakis ${ }^{1}$ and K. W. Knox ${ }^{1}$ \\ ${ }^{1}$ Institute of Dental Research, 2 Chalmers Street, Surry Hills, NSW 2010, Australia \\ ${ }^{2}$ Veterans Affairs Medical Center, 1201 Northwest 16th Street, Miami, Florida 33125, USA
}

(Received 7 September 1992; revised 8 December 1992; accepted 13 January 1993)

\begin{abstract}
Streptococcus sobrinus strain 6715-13-201 was inoculated into the oral cavity of a gnotobiotic rat and then reisolated from different portions of the gastrointestinal tract. Fourteen isolates, selected on the basis of their colonial morphology, were then screened for their ability to adhere to saliva-coated hydroxyapatite (SHA) in vitro, and their ability to produce extracellular polysaccharide from sucrose, and low $\mathrm{pH}$ in glucose broth. Certain isolates were also tested for their cariogenic potential as monoinfectants in gnotobiotic rats. All isolates differed in their abilities to adhere to SHA, with most showing an increased level of adhesion in the presence of sucrose, but this did not correlate with their ability to be aggregated by dextran. Most isolates were capable of producing glucosyltransferases (with only one exception) and dextranases (also one exception). There was more variability in the production of dextranase inhibitor. No isolate was capable of producing dextranase inhibitor in the absence of dextranase production. There were no correlations between the ability of isolates to adhere in vitro or produce/utilize polysaccharides and their ability to produce caries in vivo. Due to the differences between strains in their abilities to adhere, produce polysaccharides, utilize polysaccharides or produce a low $\mathrm{pH}$ and the lack of correlation between any of these parameters and cariogenicity, the results suggest that the ability of strains to colonize and produce caries depends on a number of different characteristics, no one of which is essential.
\end{abstract}

\section{Introduction}

Dental caries occurs when tooth enamel is dissolved by acids, particularly lactic acid produced by the fermentation of carbohydrates by plaque bacteria. The mutans streptococci have been associated with the development and progression of dental caries in humans (Shklair et al., 1974; Huis in't Veld et al., 1979), with the species $S$. mutans and $S$. sobrinus being most frequently isolated from human dental plaque. Strains of mutans streptococci have been examined for their ability to produce caries in gnotobiotic animals (Willcox et al., 1990; Fitzgerald et al., 1960; Drucker \& Green, 1981) and certain strains can produce caries on all surfaces of the teeth.

Dental plaque formation, and ultimately the production of carious lesions on the teeth, requires that bacteria adhere to the tooth surface or accumulate by adhering to other (adherent) bacteria, or to bacterial or

${ }^{*}$ Author for correspondence. Tel. 6122113091 ; fax 6122820368.

Abbreviations: EPS, extracellular polysaccharide; SHA, salivacoated hydroxyapatite; BHI, brain heart infusion. host products. For mutans streptococci, adhesion is mediated by bacterial surface components, and considerable emphasis has been given to the protein variously called P1, I/II, IF and B (Forester et al., 1983) which has been implicated in the adhesion of mutans streptococci to the tooth surface (Lee et al., 1989; Takahashi et al., 1989). A cross-reacting antigen in $S$. sobrinus has been named SpaA (Goldschmidt \& Curtiss, 1990). Attention has also been directed towards the extracellular polysaccharides that streptococci can produce from sucrose using either the glucose moiety to produce glucan or the fructose moiety to produce fructan (Birkhed et al., 1975; Trautner et al., 1981). Early work with $S$. sobrinus strains demonstrated that they required glucan synthesis for adhesion. The fructans or glucans may also act as carbohydrate reserves, and some members of the $S$. mutans group produce fructanase and dextranase (Jacques et al., 1985; Walker et al., 1981) which degrade the polysaccharides. Studies using mutants of mutans streptococci have shown that adhesion, production of extracellular polysaccharides and degradative enzymes may be important cariogenic traits (reviewed by Tanzer et al., 1985).

S. sobrinus strain 6715-13-201 has been used 
extensively in animal caries experiments (Tanzer et al., 1985) and accordingly was chosen for this study where reisolates from the gastrointestinal tract of a rat were compared for their cariogenicity, in vitro adhesion and polysaccharide production. The hypothesis to be tested was that adhesion and polysaccharide production are key elements in caries production by $S$. sobrinus.

\section{Methods}

Bacterial strains. Streptococcus sobrinus strain 6715 was derived from passage through hamsters of strain K1-R, a streptomycin-resistant mutant of the original human isolate K1. Strain 6715-13WT was isolated after passages of strain 6715 through rats and hamsters (Freedman \& Tanzer, 1974; personal communication, J. M. Tanzer). Strain 6715-13-201 is a mutant of 6715-13WT, selected because it lacks dextranase activity, and was constructed by Freedman \& Tanzer (1982) using chemical mutagenesis.

Selection of isolates from the gastrointestinal tract of a gnotobiotic rat monoinfected with S. sobrinus 6715-13-201. An outbred germ-free Sprague-Dawley rat was maintained in a sterile isolator (Fitzgerald $e t$ al., 1989) and fed radiation-sterilized diet 2000 (Keyes \& Jordan, 1964). Strain 6715-13-201 was inoculated $(0.2 \mathrm{ml})$ into the mouth of the rat and allowed to establish for $60 \mathrm{~d}$. The animal was killed humanely after $60 \mathrm{~d}$. Sections of the gastrointestinal tract were then removed aseptically, and the contents were removed and weighed. The tissue was then washed in sterile saline, bottled and weighed. The contents and tissue were separately homogenized and serial dilutions were plated on Mitis-Salivarius agar (MS; Difco) containing $200 \mu \mathrm{g}$ streptomycin $\mathrm{ml}^{-1}$. After $48 \mathrm{~h}$ incubation, the morphology (rough or smooth) of colonies was recorded and isolates were selected for further examination (Table 1).

Growth and biochemical characterization. Strains were grown in brain-heart infusion (BHI; Oxoid) supplemented with $0.3 \%$ yeast extract (Difco), and $0.074 \mathrm{MBq} \mathrm{ml}^{-1}{ }^{3} \mathrm{H}$-labelled thymidine for adhesion experiments, at $37^{\circ} \mathrm{C}$ for $24 \mathrm{~h}$. Cells were then washed three times in phosphate-buffered saline [PBS $\left(\mathrm{g} \mathrm{l}^{-1}\right): \mathrm{NaCl}, 8 ; \mathrm{KCl}, 0 \cdot 2$; $\left.\mathrm{NaH}_{2} \mathrm{PO}_{4}, 0 \cdot 2 ; \mathrm{KH}_{2} \mathrm{PO}_{4}, 2 \cdot 9\right]$ and finally resuspended at $\mathrm{OD}_{660}=1 \cdot 0$ $\left(1 \times 10^{9}\right.$ c.f.u. $\left.\mathrm{ml}^{-1}\right)$ unless otherwise stated. The final $\mathrm{pH}$ produced in glucose broth was recorded after growth for $18 \mathrm{~h}$ at $37^{\circ} \mathrm{C}$. To determine the ability of strains to produce intracellular, iodophilic polysaccharides, they were grown in $0.5 \%$ glucose broth for $18 \mathrm{~h}$ at $37^{\circ} \mathrm{C}$. Cells were removed by centrifugation $(10000 \mathrm{~g}, 10 \mathrm{~min})$ and the cell pellet was then stained with Lugol's iodine. If cells have produced intracellular polysaccharide, they stain blue-black or dark brown (a negative result is indicated by no change from the iodine colouration). The possession of serotype polysaccharides was measured by incubating washed cells with fluorescein-labelled rabbit IgG specific for serotype polysaccharides $a, b, c, d, e, f$ and $g$, and then examining them by fluorescence microscopy.

Adhesion to saliva-coated hydroxyapatite (SHA). This method has been published previously (Willcox \& Knox, 1990, 1991). Briefly, whole unstimulated saliva was collected from one of us (M.D.P.W.), clarified by centrifugation $(5000 \mathrm{~g}, 15 \mathrm{~min})$ and allowed to coat $20 \mathrm{mg}$ hydroxyapatite at ambient temperature for $1 \mathrm{~h}$. Unadsorbed salivary material was removed by washing three times in PBS. Radiolabelled bacteria were allowed to interact with SHA at $37^{\circ} \mathrm{C}$ for $2 \mathrm{~h}$. After $2 \mathrm{~h}$, non-absorbed bacteria were removed by washing three times in PBS and the amount of radioactivity associated with the SHA was measured. Each strain was tested on two separate occasions, each of three assays. To assess the effect of sucrose on adhesion, bacteria were resuspended in half the volume of buffer that gave $\mathrm{OD}_{660}=1 \cdot 0$; an equal volume of $10 \%$ sucrose was then added and the assays were repeated.

Aggregation of cells by dextran and sucrose. Cells were washed three times in buffer and then resuspended to $\mathrm{OD}_{660}=1.0$ in the assay buffer (100 mM-sodium phosphate, pH 6.5, $40 \mathrm{~mm}$-sucrose, $10 \mathrm{~mm}$-sodium fluoride, $0 \cdot 1 \mathrm{~mm}$-histidine and $0.04 \%$ dextran T10). The optical density was compared to that of control cells resuspended in buffer lacking dextran and sucrose at time zero and after $2 \mathrm{~h}$ incubation at ambient temperature. Experiments were repeated three times.

Possession of cell surface protein P1. The method of Wyatt et al. (1988), boiling in SDS, was used to extract cell-surface P1. The extract was then subjected to SDS-PAGE on $4-15 \%(w / v)$ gradient gels, blotted onto nitrocellulose and probed with antisera to P1 (Forester et al., 1983). Reactive bands were seen by secondary probing with goat alkaline-phosphatase-labelled anti-rabbit IgG and developing with fast blue BB salt (Sigma). The experiments were repeated on two separate occasions.

Glucosyltransferase, dextranase and dextranase inhibitor production. Cultures were grown in BHI for $18 \mathrm{~h}$ and centrifuged, and the supernatant was concentrated six-fold by placing in dialysis tubing and then immersing in polyethylene glycol flakes. Cells were washed once in $0.85 \% \mathrm{NaCl}$ and then incubated in a $1 \%(\mathrm{w} / \mathrm{v})$ solution of sodium lauroylsarcosinate (SLS; Jenkinson, 1986) for $60 \mathrm{~min}$ and then removed by centrifugation. The cell extract and concentrated culture fluid were heated at $100{ }^{\circ} \mathrm{C}$ for $5 \mathrm{~min}$ and subjected to SDS-PAGE in a $7.5 \%$ $(\mathrm{w} / \mathrm{v})$ gel at constant $120 \mathrm{~V}$. All experiments were repeated.

Production of cell-bound and extracellular glucosyltransferase (GTF). Following electrophoresis of proteins from either the supernatants or cell-surface, the gels were shaken for $90 \mathrm{~min}$ in $50 \mathrm{~mm}$-Tris $/ \mathrm{HCl}$, $\mathrm{pH} 7.5$, containing $1 \mathrm{mM}-\mathrm{CaCl}_{2}$, transferred to a sucrose solution $\left(50 \mathrm{~mm}-\mathrm{NaPO}_{4}, \mathrm{pH} 6.5,1 \%(\mathrm{w} / \mathrm{v})\right.$ sucrose, $1 \%(\mathrm{v} / \mathrm{v})$ Triton $\mathrm{X} 100$, $1 \mathrm{~mm}-\mathrm{CaCl}_{2}, 0.02 \%$ dextran T10) and incubated for $24 \mathrm{~h}$ at $37^{\circ} \mathrm{C}$ with shaking. The gel was then fixed in $75 \%(\mathrm{v} / \mathrm{v})$ ethanol for $30 \mathrm{~min}$ and stained with periodic acid/Schiff's reagent to detect GTFs synthesizing both insoluble and soluble polysaccharides.

Production of dextranase and dextranase inhibitor. The proteins were separated on $7.5 \%(\mathrm{w} / \mathrm{v})$ SDS-PAGE gels containing $5 \mathrm{mg}$ blue dextran $2000 \mathrm{ml}^{-1}$ (Pharmacia). Gels were incubated for $18 \mathrm{~h}$ at $37^{\circ} \mathrm{C}$ with shaking, in $0.2 \mathrm{M}$-citrate buffer, $\mathrm{pH} 6.0$, containing $1 \%(\mathrm{v} / \mathrm{v})$ Triton $\mathrm{X} 100$. At the end of the incubation, dextranase bands were seen as transparent bands in a blue gel. In order to detect dextranase inhibitor bands, the gels were incubated for $18 \mathrm{~h}$ at $37^{\circ} \mathrm{C}$ in $0.2 \mathrm{M}$-citrate buffer, pH 6.0 , containing $1 \%(\mathrm{v} / \mathrm{v})$ Triton $\mathrm{X} 100$ and $500 \mathrm{mU}$ dextranase. (Dextranase was obtained by ammonium sulphate precipitation of the culture supernatant of $S$. sobrinus K1-R, a known dextranase producer (Walker et al., 1981), and kindly supplied by Dr G. J. Walker, Institute of Dental Research). After incubation, the inhibitor bands were seen as blue bands in a clear gel.

The levels of GTF, dextranase and dextranase inhibitor production were assessed independently by three people and expressed as a range from +++ (high levels) to 0 (no detectable level)

Caries assay of reisolates. The cariogenic potential of strains was assessed in germ-free Sprague-Dawley rats using an abbreviated caries test procedure (Fitzgerald et al., 1981). Briefly, weanling germ-free animals were infected orally by swabs of the respective strains and maintained on irradiated diet 2000 (Keyes \& Jordan, 1964) for $30 \mathrm{~d}$. The animals were killed humanely by chloroform inhalation and the jaws were defleshed. The severity of caries was assessed in the first two mandibular molars using scores from 0 to 4 to cover the range from no caries to complete loss of the tooth.

Statistical analysis of data. For experiments designed to measure the effect of a particular treatment on a property of all strains, Wilcoxson's 
Table 1. Site of isolation of S. sobrinus strains, colonial morphology, adhesion to hydroxyapatite and aggregation of strains in the presence of dextran

\begin{tabular}{|c|c|c|c|c|c|}
\hline \multirow[b]{2}{*}{ Strain } & \multirow[b]{2}{*}{ Site of isolation } & \multirow{2}{*}{$\begin{array}{l}\text { Colonial } \\
\text { morphology* }\end{array}$} & \multicolumn{2}{|c|}{$\begin{array}{l}10^{-5} \times \text { Adhesion } \\
\text { to SHA (cells } \mathrm{mg}^{-1} \text { ) }\end{array}$} & \multirow{2}{*}{$\begin{array}{l}\text { Aggregation } \\
\text { by dextran } \\
\text { plus sucrose }\end{array}$} \\
\hline & & & Buffert & Sucrose ${ }^{\dagger}$ & \\
\hline 6715 & - & - & $2 \cdot 3 \pm 0.8$ & $8 \cdot 3 \pm 6 \cdot 0$ & 94 \\
\hline 6715-13WT & - & -- & $4 \cdot 3 \pm 1 \cdot 8$ & $7 \cdot 3 \pm 1 \cdot 5$ & 0 \\
\hline $6715-13-201$ & Parent strain & Large smooth & $3 \cdot 3 \pm 1 \cdot 5$ & $3 \cdot 8 \pm 0 \cdot 3$ & 47 \\
\hline A-1a & Oral cavity & Large smooth & $1.8 \pm 0.5$ & $2 \cdot 8 \pm 1 \cdot 3$ & 29 \\
\hline$A-2 b$ & Oral cavity & Large rough & $5 \cdot 5 \pm 1 \cdot 3$ & $13 \cdot 0 \pm 5 \cdot 3$ & 0 \\
\hline SC-1b & Stomach contents & Small rough & $1.8 \pm 0.8$ & $5 \cdot 8 \pm 2 \cdot 3$ & 4 \\
\hline SC- $-3 \S$ & Stomach contents & Large mucoid & $1 \cdot 0 \pm 0 \cdot 3$ & $7 \cdot 8 \pm 2 \cdot 3$ & 85 \\
\hline ST-1 & Stomach tissue & Large grainy & $4 \cdot 3 \pm 1 \cdot 5$ & $6 \cdot 0 \pm 3 \cdot 5$ & 70 \\
\hline ST-2b & Stomach tissue & Small watery & $1.8 \pm 0.5$ & $3 \cdot 0 \pm 0 \cdot 8$ & 0 \\
\hline DC-1a§ & Duodenal contents & Small rough & $4 \cdot 5 \pm 1 \cdot 3$ & $5 \cdot 0 \pm 1 \cdot 5$ & 0 \\
\hline IC-1 & Ileum contents & Small rough & $4 \cdot 5 \pm 1 \cdot 3$ & $3.0 \pm 0.8$ & 64 \\
\hline IT-1a & Ileum tissue & Small rough & $0.8 \pm 0.3$ & $12 \cdot 8 \pm 4 \cdot 3$ & 0 \\
\hline IT-2 & Ileum tissue & Large rough flat & $1 \cdot 5 \pm 0 \cdot 8$ & $1 \cdot 8 \pm 1 \cdot 0$ & 0 \\
\hline $\mathrm{CC}-1$ & Caecum contents & Small rough & $1 \cdot 3 \pm 0.8$ & $2 \cdot 5 \pm 1 \cdot 3$ & 0 \\
\hline $\mathrm{CC}-3$ & Caecum contents & Small rough & $6 \cdot 5 \pm 2 \cdot 0$ & $14 \cdot 3 \pm 8 \cdot 0$ & 0 \\
\hline CT-3 & Caecum tissue & Large watery & $2 \cdot 0 \pm 0 \cdot 8$ & $2 \cdot 5 \pm 1 \cdot 0$ & 0 \\
\hline
\end{tabular}

* Examined after growth on Mitis-Salivarius agar.

$\dagger$ Cells incubated in the absence (buffer) or presence (sucrose) of sucrose. Figures are the means of two cultures and three replicates per culture $\pm \mathrm{SD}$.

$\$ 100 \%$ aggregation was indicated by an $\mathrm{OD}_{660}$, after settling of aggregates, equal to that of sterile buffer. Results are means of three separate experiments. Standard deviation was always less than $10 \%$ of the mean value.

$\S$ Strains which autoaggregate.

sum rank test was employed. For correlations between different tests, Pearson's correlation coefficient was calculated Newman-Keuls multiple range test ANOVA was used to test for differences between caries values.

\section{Results}

\section{Isolation of strains and preliminary characterization}

Reisolated strains of $S$. sobrinus 6715-13-201 were obtained from MS plates inoculated with the gastrointestinal tissues or luminal contents of a gnotobiotic rat monoinfected with the micro-organism for $60 \mathrm{~d}$. The total concentration in terms of c.f.u. per gram of tissue (T) or contents (C) of the stomach (S), duodenum (D), ileum (I) or caecum (C) were: ST, $3.5 \times 10^{3}$; SC, $2.0 \times 10^{5}$; DT, $1.0 \times 10^{3}$; DC, $2.9 \times 10^{5}$; IT, $8.9 \times 10^{4}$; IC, $4.0 \times 10^{8}$; CT, $1.4 \times 10^{7} ; \mathrm{CC}, 2.2 \times 10^{9}$. An oral swab (A) contained $3.0 \times 10^{3}$ c.f.u. Subcultures made from these plates on the basis of predominant colony morphology are listed in Table 1. Approximately equal numbers of different colonial variants were seen, regardless of site of isolation, and in separate experiments similar findings were noted with other rats. The colonial morphologies were stable upon passage of strains in vitro.

Variation in the rate of fermentation of mannitol and sorbitol was noted for isolates (unpublished). All strains produced a final $\mathrm{pH}$ of $4 \cdot 1$ after growth in glucose broths and no strain was capable of producing iodophilicintracellular polysaccharides. All strains reacted with fluorescein-labelled rabbit antiglobulin to $S$. sobrinus B13 (serotype $g$ ), through we have since shown that the amount of the serotype $g$ polysaccharide may differ (data not shown). No strains cross-reacted with antisera to serotypes $a, b, c, d, e$ or $f$.

\section{Adhesive characteristics}

Adhesion to $S H A$. The relative abilities of strains to adhere to SHA are shown in Table 1. All strains were fairly poor adherers to SHA, with strain CC-3 giving the highest adhesion of $6.5 \times 10^{5}$ cells $\left(\mathrm{mg} \mathrm{SHA}^{-1}\right)$, and strain IT-1a giving the lowest adhesion of $8.0 \times 10^{4}$ cells $(\mathrm{mg}$ SHA $)^{-1}$. The site of isolation of the strains did not correlate with adhesion to SHA, with strains isolated from the oral cavity of rats showing a range of adhesive values similar to that for strains isolated elsewhere. Sucrose in the buffer increased the adhesion of most strains $(P<0.025)$ and in no case did sucrose significantly decrease adhesion.

Aggregation of cells by dextran and sucrose. Table 1 also shows that both stock strains and reisolates displayed differing aggregating abilities. For the reisolates, only 4 out of 13 gave $>10 \%$ aggregation, with strains SC-3, ST-1 and IC-1 giving values greater than their parent strain (6715-13-201). 


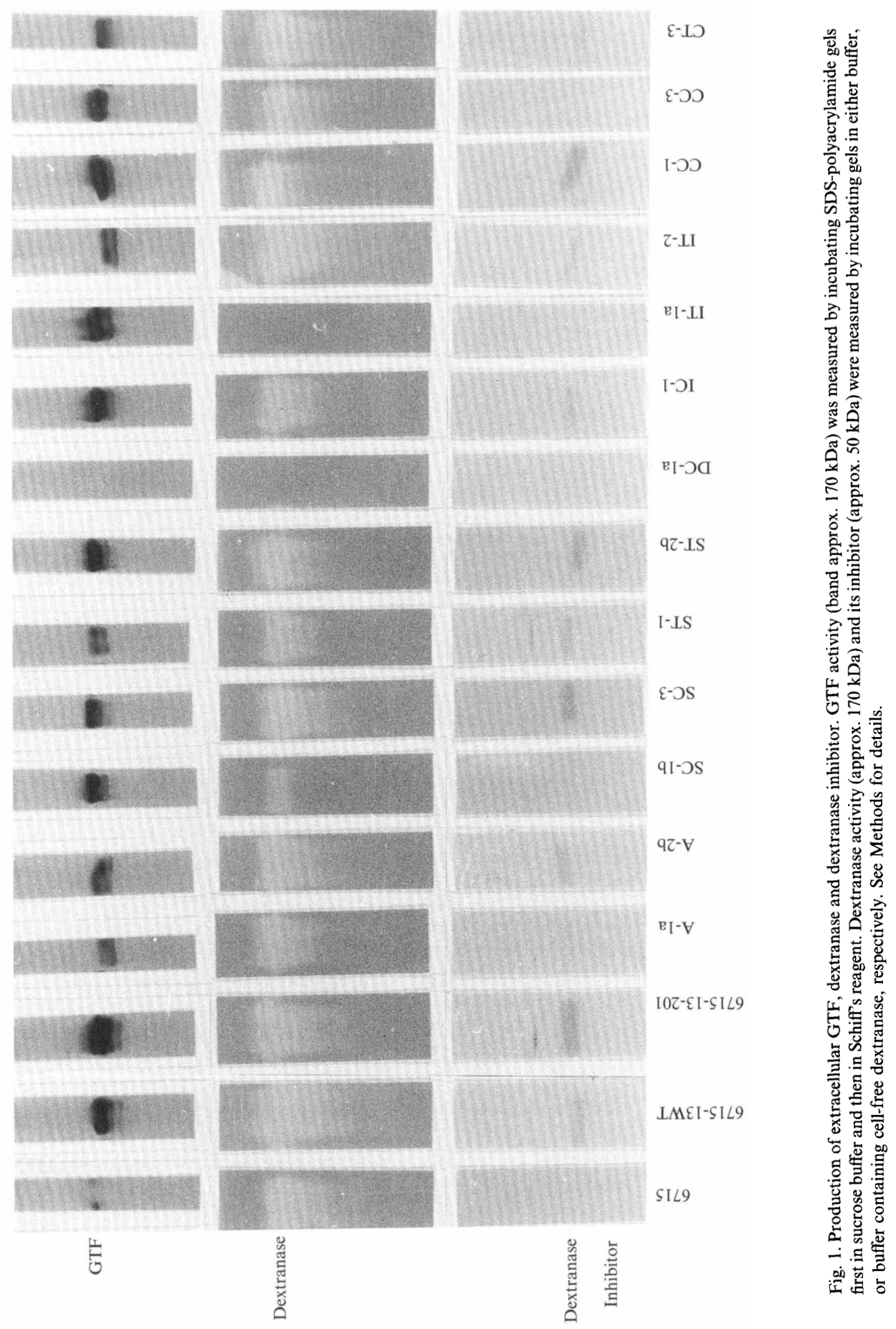


Table 2. Production of GTF, dextran and dextranase inhibitor

\begin{tabular}{lccc}
\hline \hline & \multicolumn{3}{c}{ Production of: } \\
\cline { 2 - 4 } Strain & GTF* & Dextranase $t$ & $\begin{array}{c}\text { Dextranase } \\
\text { inhibitor }\end{array}$ \\
\hline 6715 & + & +++ & $+/-$ \\
6715-13WT & +++ & +++ & ++ \\
6715-13-201 & +++ & +++ & +++ \\
A-1a & ++ & +++ & $+/-$ \\
A-2b & ++ & $+++\S$ & $+\S$ \\
SC-1b & +++ & ++ & 0 \\
SC-3 & +++ & +++ & ++ \\
ST-1 & ++ & +++ & + \\
ST-2b & +++ & +++ & ++ \\
DC-1a & 0 & 0 & 0 \\
IC-1 & +++ & +++ & + \\
IT-1a & $+++\S$ & 0 & 0 \\
IT-2 & ++ & $+++\S$ & $+\S$ \\
CC-1 & +++ & ++ & +++ \\
CC-3 & +++ & +++ & $+1-$ \\
CT-3 & ++ & +++ & + \\
\hline \hline
\end{tabular}

* GTF production was estimated from the degree of Schiff's staining in Fig. 1 by three independent observers.

$\uparrow$ Dextranase production was estimated from the degree of destaining of blue dextran in Fig. 1 by three independent observers.

$\ddagger$ Dextranase inhibitor production was assessed as the amount of blue dextran remaining (Fig. 1) after incubation of SDS-polyacrylamide gels with dextranase by three independent observers.

$\S$ Activity or inhibitor observed in SLS extracts of cells.

Table 3. Cariogenicity of strains in monoinfected germfree rats

Germ-free rats were infected orally with an overnight broth culture of the appropriate strain and maintained on a high sucrose diet for $30 \mathrm{~d}$. Data are means of 5 experiments $\pm \mathrm{SD}$.

\begin{tabular}{lc}
\hline \hline Strain & Caries Score \\
\hline 6715-13-201 & $1 \cdot 28 \pm 0 \cdot 31$ \\
SC-3 & $0 \cdot 68 \pm 0 \cdot 28$ \\
ST-2b & $0 \cdot 43 \pm 0 \cdot 12$ \\
DC-1a & $0 \cdot 54 \pm 0 \cdot 11$ \\
CC-1 & $0 \cdot 68 \pm 0 \cdot 14$ \\
CT-3 & $0 \cdot 53 \pm 0 \cdot 17$ \\
\hline
\end{tabular}

Detection of cross-reacting P1. The Western blot for cell-surface $\mathrm{SpaA}$ protein demonstrated that all strains, with the exception of SC-3 and ST-1, carried the protein. The reactive band was approximately $200 \mathrm{kDa}$ in molecular mass, and this corresponded to a positive control of purified P1 from S. mutans Ingbritt (Forester et al., 1983).

\section{Production of glucosyltransferase, dextranase and} dextranase inhibitor

Glucosyltransferase production. Fig. 1 demonstrates that all strains, with the exception of strain DC-1a, released glucosyltransferase into the culture medium.
The level of activity of both the stock strains and reisolates varied, with strain 6715 producing a low activity, strain 6715-13WT producing high activity, and strain CC-1 producing the highest activity for the reisolates. Only strain IT-1a showed activity in gels after SLS extraction and staining with Schiff's reagent, indicating the production of cell-bound GTF activity producing soluble dextran (Table 2).

Production of dextranase and dextranase inhibitor. Most strains produced extracellular dextranase activity associated with a band of approximately $170 \mathrm{kDa}$ (Fig. 1 ; Table 2), although five of the reisolates had a reduced activity compared with the parent strain. After SLS extraction of surface proteins, only strains A-2b and IT-2 showed dextranase activity (Table 2), and the dextranase of strain A-2b was approximately $97 \mathrm{kDa}$.

The ability of strains to produce extracellular dextranase inhibitor varied widely between the stock strains and the reisolates (Fig. 1; Table 2). After SLS extraction of proteins, only strains A- $2 \mathrm{~b}$ and IT-2 showed inhibitor bands (Table 2), each with an estimated molecular mass of approximately $50 \mathrm{kDa}$.

\section{Cariogenicity of selected strains in gnotobiotic rats}

Table 3 shows the relative cariogenicity of six strains selected on the basis of differences in the above in vitro tests. The highest activity score was given by strain $6715-$ 13-201 and the lowest score by strain ST-2b. Strain 671513-201 gave a statistically $(P<0.05)$ greater caries score than the reisolates which were statistically similar to each other.

\section{Statistical correlations between data sets}

The following pairs were tested for correlations: aggregation by dextran and increase in adhesion in the presence of sucrose (i.e. [adhesion to SHA plus sucrose] [adhesion to SHA]); possession of P1-CRA and adhesion to SHA; possession of P1-CRA and increase in adhesion to SHA in the presence of sucrose; and (in specific instances) cariogenicity and adhesion to SHA or production/utilization of polysaccharides. There were no correlations between any of the data sets.

\section{Discussion}

This study clearly demonstrates that passage through and colonization of the gastrointestinal tract of a gnotobiotic rat by $S$. sobrinus 6715-13-201 profoundly affects phenotypic traits and that these traits are revealed after a relatively short colonization time $(60 \mathrm{~d})$. The strains used in this study were all derivatives of $S$. sobrinus strain $\mathrm{K} 1$, an isolate from the human oral cavity 
that has been subjected to animal passage on numerous occasions (Freedman \& Tanzer, 1974). Whilst there is no information in the literature on the occurrence of variants after animal passage of strain $\mathrm{K} 1$, alterations could have occurred but not been noted. Strain 6715-13201 does not show variants upon subculture in vitro (data not shown) and therefore it can be concluded that the variants shown in this study must be the direct result of in vivo passage. Although the isolates were selected from the gastrointestinal tract of one rat, other experiments have shown that strain 6715-13-201 shows similar results in other rats.

The isolation of strains from specific sites in the gastrointestinal tract was not reflected in their ability to adhere to surfaces in vitro. The ability to adhere directly to the tooth surface may not be essential for strains to become part of the oral flora. Previous studies have demonstrated that $S$. sobrinus strains require sucrose for attachment in vitro to SHA (Koga \& Inoue, 1978) and the present investigation demonstrates that sucrose increases adhesion of the $S$. sobrinus strains. However, the strains were able to adhere in the absence of sucrose, indicating that they must possess adhesins capable of interacting with molecules in the pellicle other than GTF or dextran. Mechanisms of specific adhesion have focused on protein P1 that is found on the surface of $S$. mutans strains (Wyatt et al., 1988). Although protein P1 has been shown to mediate adhesion to SHA for S. mutans strains, there was no correlation between possession of P1-CRA (SpaA) by S. sobrinus and adhesion or site of isolation. There is information suggesting that $S$. sobrinus strains attach to several different salivary pellicle molecules (Gibbons et al., 1986) and this may be mediated by molecules other than SpaA. SpaA of $S$. sobrinus strains may be involved in the sucrose-induced aggregation of this species (Goldschmidt \& Curtiss, 1990; Takahashi et al., 1989), although in the present investigation we found no correlation between the possession of P1-CRA and increase in adhesion in the presence of sucrose.

Adhesion to surfaces is important in initial colonization, whereas subsequent accumulation may depend on other factors and lead to the successful incorporation of non-adherent strains or species in an ecosystem. Bacteria may accumulate by synthesizing extracellular molecules and subsequently binding to these. With one exception, all strains were capable of synthesizing dextrans from sucrose, whereas only $47 \%$ of strains were aggregated by dextran, suggesting that the binding of preformed dextran is not mediated by glucosyltransferase, indeed $S$. sobrinus strain 6715 has been shown to produce a glucanbinding protein ( $\mathrm{Lu} \mathrm{Lu}$ et al., 1992).

The production of dextrans and their subsequent utilization as energy reserves has been postulated to be important in maintaining a low $\mathrm{pH}$ and thus in demineralizing enamel. Therefore, the ability of strains to produce dextranase and their ability to regulate the production of dextranase may be important traits in caries production. Most strains produced dextranase, and even strain 6715-13-201, that had been selected on the basis of its inability to produce dextranase, was shown to have dextranase activity on SDS-PAGE. However, strain 6715-13-201 produced large amounts of dextranase inhibitor, which may explain why no dextranase activity was seen on blue dextran agar plates. There was a wide variation in the ability of strains to produce dextranase inhibitors but no strain was shown to be able to produce a dextranase inhibitor without the production of dextranase.

Comparisons were made between selected strains for their ability to produce caries as monoinfectants in gnotobiotic rats. The caries experiments were conducted for $30 \mathrm{~d}$, as this was a minimal time for the detection of fissure caries lesions, and it was hoped that variations in the bacteria would be minimal, indeed oral swabs of rats after $30 \mathrm{~d}$ showed no rough/smooth colonial variants. Although there were variations in the ability of strains to cause caries, there was no clear relation between the ability to produce the disease and any in vitro characteristics. Therefore, $S$. sobrinus strains may be able to inhabit dental plaque and produce dental caries using a variety of different strategies.

In conclusion, this series of experiments has demonstrated that changes in a wide range of phenotypic traits may occur in $S$. sobrinus on passage through the gastrointestinal tact of germ-free rats. Whilst only a single strain has been studied in detail, it has been noted (data not presented) that other strains of $S$. sobrinus also demonstrate colonial variation after passage in a gnotobiotic rat. The study also draws attention to the different mechanisms mutans streptococci strains employ to become part of the normal flora, where loss of a single characteristic may not preclude successful colonization. The results indicate that no single trait, of those studied, is dominant in the ability of the strains to produce caries; a number of factors acting in concert may be essential and the nature of these factors may differ between strains.

This work was supported by the National Health and Medical Research Council of Australia and the Medical Research Service, US Department of Veterans Affairs.

\section{References}

Birkhed, D., Rosell, K.-G. \& Granath, K. (1979). Structure of extracellular water-soluble polysaccharides synthesised from sucrose by oral strains of Streptococcus mutans, Streptococcus salivarius, Streptococcus sanguis and Actinomyces viscosus. Archives of Oral Biology 24, 387-389. 
DRUCKER, D. B. \& GREEN, R. M. (1981). The relative cariogenicity of different streptococci in the gnotobiotic WAG/RIJ rat. Archives of Oral Biology 26, 599-606.

Fitzgerald, R. J., Jordan, H. V. \& Stanley, H. R. (1960). Experimental caries and gingival pathologic changes in the gnotobiotic rat. Journal of Dental Research 39, 923-935.

Fitzgerald, R. J., Adams, B. O., Sandham, H. J. \& Abhyankar, S. (1989). Cariogenicity of a lactate dehydrogenase-deficient mutant of Streptococcus mutans serotype $\mathrm{c}$ in gnotobiotic rats. Infection and Immunity 57, 823-826.

FORESTER, H., HUNTER, N. \& KNOX, K. W. (1983). Characteristics of a high molecular weight extracellular protein of Streptococcus mutans. Journal of General Microbiology 129, 2779-2788.

FreEdman, M. L. \& TANZer, J. M. (1974). Dissociation of plaque formation from glucan-induced agglutination in mutants of Streptococcus mutans. Infection and Immunity 10, 189-196.

FreEdMan, M. L. \& TANZER, J. M. (1982). Use of mutants to study the glucan-associated pathophysiology of Streptococcus mutans. In Microbiology 1982, pp. 186-190. Edited by D. Schlessinger. Washington DC. American Society for Microbiology.

Gibbons, R. J., Cohen, L. \& HaY, D. I. (1986). Strains of Streptococcus mutans and Streptococcus sobrinus attach to different pellicle receptors. Infection and Immunity 52, 555-561.

GoldSChMidT, R. M. \& CuRTiss, R., III (1990). Cross-reactivity between the immunodominant determinant of the antigen I component of Streptococcus sobrinus SpaA protein and surface antigens from other members of the Streptococcus mutans group. Infection and Immunity 58, 2276-2282.

Huis in't Veld, J. H., van Palenstein-Helderman, W. H. \& BackerDiRKs, A. (1979). Streptococcus mutans and dental decay in humans - a bacteriological and immunological study. Antonie van Leeuwenhoek 45, 25-33.

JACQUES, N. A., MorRy-Jones, J. G. \& Walker, G. J. (1985). Inducible and constitutive formation of fructanase in batch and continuous cultures of Streptococcus mutans. Journal of General Microbiology 131, 1625-1633.

JENKINSON, H. F. (1986). Cell-surface proteins of Streptococcus sanguis associated with cell hydrophobicity and coaggregation properties. Journal of General Microbiology 132, 1575-1589.

Keyes, P. H. \& Jordan, H. V. (1964). Periodontal lesions in the syrian hamster. III. Findings related to an infectious and transmissible component. Archives of Oral Biology 9, 377-400.

KoGA, J. \& INOUE, M. (1978). Cellular adherence, glucosyltransferase adsorption and glucan synthesis of Streptococcus mutans AHT mutants. Infection and Immunity 19, 402-410.
Lee, S. F., Progulske-Fox, A., Erdos, G. W., Piacentini, D. A., Ayakawa, G. Y., Crowley, P. J. \& Bleiweis, A. S. (1989). Construction and characterisation of isogenic mutants of Streptococcus mutans deficient in major surface protein antigen P1 (I/II). Infection and Immunity 57, 306-313.

Lu Lu, Singh, J. S., Galperin, M. Y., Drake, D., Taylor, K. G. \& DOYLE, R. J. (1992). Chelating agents inhibit the activity and prevent expression of streptococcal glucan-binding proteins. Infection and Immunity 60, 3807-3813.

Shklair, I. L., Keene, H. J. \& Cullen, P. (1974). The distribution of Streptococcus mutans on the teeth of two groups of naval recruits. Archives of Oral Biology 19, 199-202.

Takahashi, I., OKahashi, N., Sasakawa, C., Yoshikawa, M., HaMadas, S. \& KogA, T. (1989). Homology between surface protein antigen genes of Streptococcus sobrinus and Streptococcus mutans. FEBS Letters 249, 383--388.

Tanzer, J. M., Freedman, M. L. \& Fitzgerald, R. J. (1985). Virulence of mutants defective in glucosyl transferase, dextranmediated aggregation, or dextranase activity. In Molecular Basis of Oral Microbial Adhesion, pp. 204-211. Edited by S. E. Mergenhagen \& B. Rosan. Washington DC: American Society for Microbiology.

Trautner, K., Felgenhauer, B. \& Reider, H. (1981). Extracellular polysaccharide synthesised by the oral bacterium Streptococcus mutans of serotype a to e in vitro. Archives of Oral Biology 26, $1005-1013$

Walker, G. J., Pulkownik, A. \& Morrey-Jones, J. G. (1981). Metabolism of the polysaccharides of human dental plaque: Release of dextranase in batch cultures of Streptococcus mutans. Journal of General Microbiology 127, 201-208.

Willcox, M. D. P. \& KNox, K. W. (1990). Surface-associated properties of Streptococcus milleri group strains and their potential relation to pathogenesis. Journal of Medical Microbiology 31, 259-270.

Willcox, M. D. P. \& KNox, K. W. (1991). A comparison of the adhesion profiles and cell surface characteristics of Streptococcus mitis with those of other members of the Streptococcus sanguis group. Microbial Ecology in Health and Disease 4, 61-72.

Willcox, M. D. P., Drucker, D. B. \& GreEn, R. M. (1990). Comparative cariogenicity and dental plaque forming ability in gnotobiotic rats of four species of mutans streptococci. Archives of Oral Biology 34, 825-828.

Wyatt, J. E., Willcox, M. D. P., Russell, R. R. B. \& Handley, P. S. (1988). Fibrillar strains of Streptococcus sanguis biotype I carry a surface protein which cross-reacts with antigen B from Streptococcus mutans Ingbritt. Oral Microbiology and Immunology 3, $162-168$. 